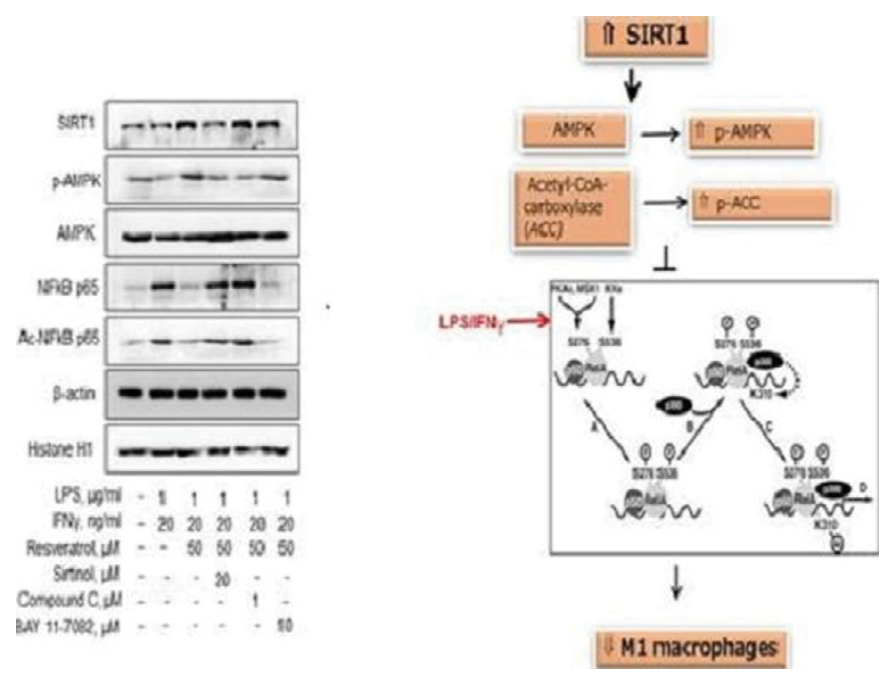

Disclosure of Interest: None declared

DOI: 10.1136/annrheumdis-2017-eular.2646

\section{AB0108 DECREASED EXPRESSION OF PTPN22 GENE IN PATIENTS WITH RHEUMATOID ARTHRITIS CARRYING THE RISK ALLELE OF PTPN22 RS2488457 POLYMORPHISM}

S. Remuzgo-Martínez ${ }^{1}$, S. Castañeda ${ }^{2}$, A. Corrales ${ }^{1}$, F. Genre ${ }^{1}$, R. López-Mejías ${ }^{1}$, P. Moreno-Fresneda ${ }^{2}$, B. Ubilla ${ }^{1}$, V. Mijares ${ }^{1}$, V. Portilla ${ }^{1}$, J. González-Vela ${ }^{1}$, T. Pina ${ }^{1}$, G. Ocejo-Vinyals ${ }^{3}$, J. Irure-Ventura ${ }^{3}$, R. Blanco ${ }^{1}$, J. Martín ${ }^{4}$, J. Llorca ${ }^{5}$, M.A. González-Gay ${ }^{1,6}$. ${ }^{1}$ Epidemiology, Genetics and Atherosclerosis Research Group on Systemic Inflammatory Diseases, Rheumatology Department, IDIVAL, Santander; ${ }^{2}$ Rheumatology Department, Hospital Universitario la Princesa, IIS-IP, Madrid; ${ }^{3}$ Immunology Department, Hospital Universitario Marqués de Valdecilla, Santander; ${ }^{4}$ Instituto de Parasitología y Biomedicina "López-Neyra", CSIC, PTS Granada, Granada; ${ }^{5}$ Department of Epidemiology and Computational Biology, School of Medicine, University of Cantabria, and CIBER Epidemiología y Salud Pública (CIBERESP), IDIVAL; ${ }^{6}$ School of Medicine, University of Cantabria, Santander, Spain

Background: Mutations in the protein tyrosine phosphatase non-receptor 22 (PTPN22) gene are associated with numerous connective tissue and autoimmune diseases [1]. In particular, PTPN22 has been recognized as the main non-HLA genetic risk factor involved in rheumatoid arthritis (RA) susceptibility [2]. Moreover, it has been suggested that PTPN22 modulation may influence on inflammatory processes associated with RA $[3,4]$.

Objectives: To determine if PTPN22 (rs2476601, rs33996649 and rs2488457) polymorphisms, associated with RA, may influence on PTPN22 expression in RA patients compared to healthy controls. Moreover, the association between PTPN22 expression in patients with RA and their clinical characteristics was studied.

Methods: PTPN22 messenger RNA (mRNA) expression was quantified by quantitative real-time PCR in peripheral blood samples from 42 RA patients and 24 healthy controls. PTPN22 rs2476601 (G>A), PTPN22 rs3399649 (C>T), and PTPN22 rs2488457 (C>G) single-nucleotide polymorphisms (SNP) were genotyped by TaqMan SNP genotyping assays. Differences in PTPN22 expression between patients and controls were analyzed by Student's $t$ test, according to their genotype. Correlation coefficients were also assessed between PTPN22 expression in RA patients and their clinical characteristics.

Results: A significant down-regulation of PTPN22 expression in patients with RA carrying PTPN22 rs2488457 risk allele (G) compared to controls was observed (relative mean values of PTPN22 mRNA levels \pm standard deviation: $2.93 \pm 0.76$ vs $4.33 \pm 0.63, p=0.0004)$. Furthermore, an inverse relationship between PTPN22 expression and disease duration $(r=-0.38, p=0.03)$ was found. These results were adjusted by sex, age at time of study and cardiovascular risk factors.

Conclusions: Our study shows for the first time that the risk allele of PTPN22 rs2488457 polymorphism influences on the down-regulation of PTPN22 in patients with RA. This result suggests a transcriptional suppression of PTPN22 gene in RA, which in turn may play an important role in disease diagnosis and progression.

\section{References:}

[1] Stanford and Bottini. Nat Rev Rheumatol 2014, 10(10):602-11.

[2] Messemaker et al. J Autoimmun 2015, 64:74-81.

[3] Ronninger et al. Genome Med 2012;4(1):2.

[4] Díaz-Gallo and Martín. Genome Med 2012;4(2):13.

Acknowledgements: This study was supported by European Union FEDER funds and "Fondo de Investigación Sanitaria" (PI12/00060 and PI15/00525) from "Instituto de Salud Carlos III" (ISCIII, Health Ministry, Spain). It was also partially supported by RETICS Programs RD12/0009 and RD16/0012 (RIER) from ISCIII. SR-M is supported by fund from the RETICS Program (RIER)
(RD16/0012/0009). FG is a recipient of a Sara Borrell postdoctoral fellowship from ISCII (CD15/00095). RL-M is supported by a "Miguel Servet tipo-l" contract from ISCIII (CP16/00033). BU is supported by funds from the RETICS Program (RIER) (RD12/0009/0013) from ISCIII (Health Ministry, Spain).

Disclosure of Interest: None declared

DOI: 10.1136/annrheumdis-2017-eular.5839

\section{AB0109 AUTOPHAGY INHIBITOR REGULATES APOPTOSIS AND PROLIFERATION OF SYNOVIAL FIBROBLASTS THROUGH THE INHIBITION OF PI3K/AKT PATHWAY IN COLLAGEN-INDUCED ARTHRITIS RAT MODEL}

S. Li, F. Li, W.J. Chen, C. Deng. Department of Rheumatology and Immunology, the Second Xiang Ya Hospital, Central South University, Changsha, Hunan,

China, Changsha, China

Background: Mounting studies have illustrated an important role of autophagy in various diseases, but few studies have reported its contribution to rheumatoid arthritis (RA) and the underlying mechanism is largely unknown.

Objectives: This study aimed to investigate whether autophagy inhibitors could regulate apoptosis and proliferation through $\mathrm{PI} 3 \mathrm{~K} / \mathrm{AKT}$ pathway in RA

Methods: RA animal model was established by collagen induction. General observations and degree of joint swelling were observed. Inflammatory response, cell survival related factors and apoptosis were also detected in synovial fibroblasts. In addition, cultured rheumatoid arthritis fibroblast-like synoviocytes (RA-FLS) were subjected to TNF- $\alpha$ treatment in vitro, and TNF- $\alpha$ induced cell autophagy, synovial cell proliferation and apoptosis were detected. Moreover, cell cycle and cytokine secretion protein, along with the above parameters, were analyzed.

Results: Results from the animal model showed that autophagy inhibitors could attenuate inflammatory reaction and synovial hyperplasia, while promoted synovial fibroblasts apoptosis. Meanwhile, inhibition of autophagy promoted cell apoptosis and reversed cell proliferation in vitro, also blocked cell in the G2/M arrest and reduced the $S$ phase cells. Furthermore, inhibition of PI3K/AKT pathway reversed TNF- $\alpha$ mediated autophagy and cytokine secretion.

Conclusions: autophagy inhibitors could mitigate inflammation response, inhibiting RA-FLS cell proliferation while promoting cell apoptosis by PI3K/AKT pathway.

References:

[1] Neumann, E., et al., Rheumatoid arthritis progression mediated by activated synovial fibroblasts. Trends in Molecular Medicine, 2010. 16(10): p. 458-68.

[2] Feng, Y., et al., The Role of Autophagy in Rheumatic Disease. Current Drug Targets, 2016.

[3] Kenific, et al., Cellular and metabolic functions for autophagy in cancer cells. Trends in Cell Biology, 2015. 25(1): p. 37-45

[4] Yan, H., et al., Suppression of experimental arthritis through AMP-activated protein kinase activation and autophagy modulation. Journal of Rheumatic Diseases \& Treatment, 2011. 1(1).

[5] Qu, Y., et al., MicroRNA-126 affects rheumatoid arthritis synovial fibroblast proliferation and apoptosis by targeting PIK3R2 and regulating PI3K-AKT signal pathway. 2016.

[6] García, S., et al., Akt activity protects rheumatoid synovial fibroblasts from Fas-induced apoptosis by inhibition of Bid cleavage. Arthritis Research \& Therapy, 2010. 12(1): p.: R33.

Acknowledgements: This work was supported by grants from the National Natural Science Foundation of China Youth Foud (81302567) and Basic scientific research service fee of Central South University (2012QNZT138) to Dr. Shu Li.

Disclosure of Interest: None declared

DOI: 10.1136/annrheumdis-2017-eular.2044

\section{AB0110 EVALUATION OF THE EFFECT OF CHUANTENGTONGBI DECOCTION ON DBA / 1 MICE CIA MODEL}

X.-Q. Wang, X.-D. Shen, X.-Y. Zhang, X. Du. Department of Traditional Chinese Medicine, School of Basic Medical Sciences, Beijing University of Chinese Medicine, Beijing, China

Background: DBA/1 mouse ( $\mathrm{H}^{\mathrm{q}}$ type) $\mathrm{CIA}$ model as a mature model of rheumatoid arthritis is widely used in pharmacology and pharmacodynamics research ${ }^{[1]}$. Chinese medicine treatment of rheumatoid arthritis has accumulated rich experience. The study of Tripterygium glycosides is quite representative, and it has been widely used in the past 30 years. Some Clinical studies showed that tripterygium glycosides treatment of rheumatoid arthritis had good effect ${ }^{[2]}$. ChuanTengTongBi decoction is also the effective prescription commonly used for the treatment of rheumatoid arthritis.

Objectives: To investigate the pathological damage degree of DBA/1 mouse $\mathrm{CIA}$ model and the effects of different doses of ChuanTengTongBi decoction on the CIA model mice.

Methods: The mice were divided into normal group, model group, leflunomide group $(3.11 \mathrm{mg} / \mathrm{kg} / \mathrm{d})$, low-dose of ChuanTengTongBi group $(0.44 \mathrm{~g} / \mathrm{ml} / \mathrm{d})$, mediumdose group $(0.88 \mathrm{~g} / \mathrm{ml} / \mathrm{d})$ and high-dose group $(1.76 \mathrm{~g} / \mathrm{ml} / \mathrm{d})$.

Results: The arthritis index (Al) was evaluated every week to determine whether the model was successful. We defined Al score $\geq 4$ as successful model (Al score 
standard:0, No swelling:1, Slight redness and swelling;2, Moderate redness and swelling of ankle; 3 , Severe redness and swelling of the entire paw;4, Maximally inflamed limb with involvement of multiple joints ${ }^{[3]}$ ). Day $28-42$, hind foot redness and swelling of the mouse continued to develop and extended to the forefoot. Compared with the normal group, incidence of CIA model group reached 100\%. Day 49, compared with the model group by joint scores, medium-dose group, high-dose group and leflunomide group have Significant differences on CIA model $(p<0.01)$. Compared with the Leflunomide group, low-dose group, medium-dose group and high-dose group have no obvious difference $(p>0.05)$. Compared with the low-dose group, medium-dose group and high-dose group have no difference $(p>0.05)$.

Table 1. Joint scores (mean \pm SD)

\begin{tabular}{lcccc}
\hline groups & $28 \mathrm{~d}$ & $35 \mathrm{~d}$ & $42 \mathrm{~d}$ & $49 \mathrm{~d}$ \\
\hline a & 0 & 0 & 0 & 0 \\
b & $8.05 \pm 1.62$ & $12.40 \pm 2.10$ & $14.68 \pm 1.77$ & $12.33 \pm 1.68$ \\
c & $8.66 \pm 0.14$ & $11.99 \pm 0.23$ & $12.10 \pm 0.23^{\star *}$ & $11.30 \pm 0.22^{\star \star}$ \\
d & $7.90 \pm 0.34$ & $11.40 \pm 0.18$ & $12.80 \pm 0.20^{\star *}$ & $12.00 \pm 0.13$ \\
e & $7.40 \pm 0.23$ & $10.90 \pm 0.13^{\star}$ & $10.40 \pm 0.44^{\star *}$ & $10.60 \pm 0.36^{\star *}$ \\
f & $8.80 \pm 0.24$ & $10.60 \pm 0.30^{*}$ & $11.30 \pm 0.22^{\star *}$ & $8.80 \pm 0.55^{\star \star}$
\end{tabular}

a. Blank group. b. Model group. c. Leflunomide group. d. Low-dose group. e. Medium-dose group. f. High-dose group. Compared with the model group, ${ }^{\star} \mathrm{p}<0.05,{ }^{* *} \mathrm{p}<0.01$.

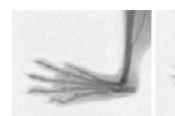

a

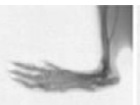

b

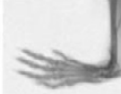

C

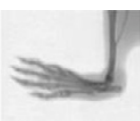

d

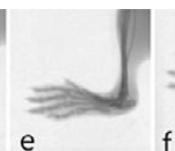

e figure 1. Ankle Joint X-ray

a.blank group b.model group c.leflunomide group d.low-dose group e.medium-dose group f.high-dose group

Conclusions: CIA model has a high morbidity, long duration, macroscopic pathological manifestation and irreversible ankle joint deformation, which is consistent with the progress of human RA disease and pathological damage. Medium-dose of ChuanTengTongBi decoction, high-dose and leflunomide group had inhibitory effect on the progress of arthritis, and the effect of high-dose was better than that of leflunomide group.

References:

[1] Brand, D.D. Rodent models of rheumatoid arthritis. Comp. Med. 55, 114122(2005).

[2] Shen S, Yang Z, Yiyang $\mathrm{H} \mathrm{U}$, et al. The Effect of Tripterygium Wilfordii glycoside on the Expression of CD_4+CD_(25) (high) Regulatory T cells, Th1 and Th2 with IgA Nephropathy[J]. Chinese Journal of Integrated Traditional \& Western Nephrology, 2013.

[3] David D Brand, Kary A Latham, \& Edward F Rosloniec. Collagen-induced arthritis. Nature Protocol.5.1270-1274(2007).

Disclosure of Interest: None declared

DOI: 10.1136/annrheumdis-2017-eular.3396

\section{AB0111 CADMIUM NANOPARTICLES CITRULLINATE INTRACELLULAR CYTOKERATINS: CADMIUM POTENTIALLY LINKS RHEUMATOID ARTHRITIS TO SMOKING AND NUMEROUS WORKING CLASS OCCUPATIONS}

D. Hutchinson ${ }^{1}$, J. Müller ${ }^{2}$, J.E. McCarthy ${ }^{3}$, Y. Gun'ko ${ }^{3}$, N. Verma ${ }^{4}$, X. Bi ${ }^{5}$, L. Di Cristo $^{3}$, L. Kickham ${ }^{3}$ D. Movia ${ }^{3}$ A. Prina-Mello ${ }^{3}$, Y Volkov ${ }^{3}{ }^{1}$ Royal Cornwall Hospital Trust, University of Exeter Medical School, Truro, United Kingdom; ${ }^{2}$ University of Basel, Switzerland, Basel., Switzerland; ${ }^{3}$ Trinity College, Dublin, Ireland; ${ }^{4}$ Nanyang Technological University; ${ }^{5}$ Bioprocessing Technology Institute, Singapore, Singapore

Background: Smoking has emerged as a consistent risk factor for ACPA positive RA, although the specific constituents of cigarette smoke that induce citrullination are unknown. It has been hypothesised that cadmium triggers RA as its inhalation links various well established risk factors for RA such as smoking (the most important environmental source of cadmium) and numerous working class occupations [1].

Objectives: To determine whether the cadmium-derived materials induce intracellular citrullination.

Methods: Human A549 lung epithelial cells were exposed to cadmium in ionic and particulate form represented by cadmium chloride and cadmium oxide, respectively, and their combinations with ultrafine carbon black (ufCB) nanoparticles produced following high temperature combustion, imitating cigarette burning Protein citrullination in cell lysates was analysed by SDS-PAGE electrophoresis with western blotting and verified by immunofluorescence staining and confocal microscopy. Target citrullinated proteins were identified by proteomic analysis. Results: Cytotoxicity studies demonstrated that cadmium compounds were toxic to the cells. Based on the results of cytotoxicity measurements, all the materials utilised in the experiments were subsequently applied to the cells in sub-toxic concentrations. Cadmium oxide, ufCB and its combination with cadmium chloride and cadmium oxide after high temperature combustion induced citrullination of multiple proteins in cultured human lung epithelial cells of A549 cell line, as demonstrated by SDS-SDS-PAGE electrophoresis and western blotting. This phenomenon develops via a peptidylargininedeiminase-dependent mechanism, as demonstrated in our previous studies [2]. The majority of citrullinated proteins were represented by the bands corresponding to the molecular weights between 55 and $72 \mathrm{kDa}$, and several less abundant bands at the level of $\sim 25 \mathrm{kDa}$ and over $130 \mathrm{kDa}$. Acidic cytokeratins of type I $(9,10)$ and basic/neutral cytokeratins type II $(1,2,5,6 \mathrm{~A}, 6 \mathrm{~B}$ and 77$)$ were identified as major intracellular citrullination targets. Immunofluorescent staining demonstrated that the citrullinated proteins were localised both in the cytoplasm and nuclei of cells exposed to cadmium particles, similar to the distribution patterns observed in cells exposed to ufCB.

Conclusions: Cadmium nanoparticle exposure facilitates post-translational citrullination of proteins.

References:

[1] Hutchinson D. Cadmium, one of the villains behind the curtain:has exposure to cadmium helped to pull the strings of seropositive rheumatoid arthritis pathogenesis all along? International journal of rheumatic diseases 2015;18:570-3.

[2] Mohamed BM, Verma NK, Davies AM, McGowan A, Crosbie-staunton K, Prina-Mello $A$, et al. Citrullination of proteins:a common post-translational modification pathway induced by different nanoparticles in vitro and in vivo. Nanomedicine 2012;7:1181-95

Acknowledgements: This work has been supported by the Higher Education Authority of Ireland, Science Foundation of Ireland through the Advanced Materials and BioEngineering Research (AMBER) project (Grant \#SFI/12/RC/2278) and the Cornwall Arthritis Trust.

Disclosure of Interest: None declared

DOI: 10.1136/annrheumdis-2017-eular.3620

\section{Spondyloarthritis - etiology, pathogenesis and animal models}

\section{AB0112 INTERFERON-REGULATED GENES (IRG) SIGNATURES DIFFERENTIATE GROUPS OF AS PATIENTS AND ARE ASSOCIATED WITH ANTI-TNF RESPONSE: PILOT DATA}

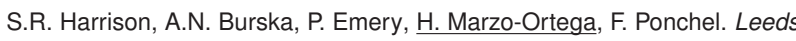
Institute of Rheumatic and Musculoskeletal Medicine, Leeds, United Kingdom

Background: Ankylosing Spondylitis (AS) is a chronic inflammatory arthritis characterised by sacroiliac/ lumbar spinal inflammation and extra-articular manifestations. Currently, TNF inhibitors (TNFi) are licensed for treatment-refractory AS; however, many patients do not respond to treatment and there is no way to predict Response/Non-Response (R/NR). The expression of several Interferon (IFN) signalling related genes (IRG) are associated with inflammatory diseases, including AS. Furthermore, an IRG expression signature has been used to predict treatment response in phase-la trials in systemic lupus erythematosus (1), demonstrating the feasibility of the use of IRG signatures as biomarkers in routine clinical practice.

Objectives: To explore whether IRG signatures differentiate groups of AS patients, and can be associated with response to TNFi in AS.

Methods: Twenty-six week-0 peripheral blood mononuclear cell (PBMC) samples

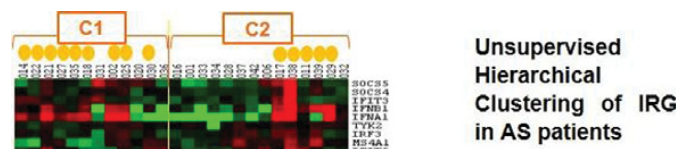

Red represents highe levels of gene expression and green represents lower levels of gene expression of the corresponding gene following

normalisation to the housekeeping gene, GAPDH. Clustering defined two groups (C1 and (2), driven by expression of the 14 IRG (blue box). Patient study numbers are listed at the top of the cluster. An orange dot adjacent to particular patient indicates that they were an ASDAS NR. 